\title{
Evaluate the Importance of Translanguaging in Language Learning Classes
}

\author{
Wanyi Liu, ${ }^{1, *}$ \\ ${ }^{1}$ University of Nottingham Ningbo China, Faculty of Humanities and Social Science, Ningbo, Zhejiang, China \\ *Corresponding author.hvywl1@nottingham.edu.cn
}

\begin{abstract}
With the increasing development of international communication, most people regard foreign language learning as a top priority and make it a part of their daily life. More and more attention is being paid to the study and application of foreign languages, which highlights the significance of choosing a proper teaching method in language learning. This essay illustrates different means of teaching in language education classrooms and makes a comparison between these different types of teaching methods. In this connection, the paper takes the approach of doing a literature review about language learning classrooms. In previous papers, various teaching patterns were examined, and in this essay, different approaches to foreign language education will be evaluated and compared. There are advantages and disadvantages of multilingual education, this essay will evaluate monolingual education and argue that it causes more negative impacts than positive impacts, and it needs more improvements. This essay will first examine the arguments in favor of monolingualism from the perspectives of both educators and students, as well as provide an introduction and evaluation of bilingual classrooms, before arguing that translanguaging can provide more benefits in language learning and highlighting its importance in bilingual education.
\end{abstract}

Keywords: monolingual education, bilingual education, online courses, trans-languaging

\section{INTRODUCTION}

With new possibilities for language policy and important implications for teachers and teacher educators, the translation stance "undermines" traditional language policy and creates space for a more equitable approach[4]. According to Lewis et al.[11], trans-languaging is a tool that can help learners gain their abilities of understanding and using both native and target languages. In foreign language teaching, whether to use students' mother tongue has always been an open question, especially in the cultural homogeneity of the educational background, most students are monolinguals[1]. During this pandemic period, online teaching and learning have become a popular trend in education, more universities are carrying out online programs and courses as well, which has a worldwide market and they need more than just one language to adapt to the cross-culture environment.

\section{CONCEPTS AND FEATURES OF MONOLINGUAL EDUCATION}

\subsection{Concepts of monolingualism}

The viewpoint called monolingual bias (MB) means that people who speak only one language - which means monolingual - are the norm and that bilinguals and multilinguals are exceptions to that norm. That is, the prototypical human is seen as having only one language. This bias can be found in the assumptions, hypotheses, and practices of many fields connected to language, so it is a quite common phenomenon. It is not surprising that people often consider the linguistic diversity of this dominant group as having a higher status, especially when they increasingly using of the language access to power or wealth. Weaker groups, by contrast, tend to use language variants that are considered "incorrect" or "bad"[7]. Because of the strong economic strength of certain English-speaking countries and its widespread, English itself gains a more dominant impact on non-English speaking regions. It is claimed that many speakers of widely communicated 
"powerful" languages such as English take it for granted that one language is normal, with people who speak two or more languages being the exception[5].

\subsection{Advantages of Monolingual Education}

It can be argued that one of the advantages of monolingual education being applied in second language learning is that it has been used widely and it is a common way of learning another language due to it creates the environment for learners to learn a foreign language in a more immersive way, especially in some English-speaking countries. According to Cummins[2], exposure to a language whether at home or school has direct impact on the achievement in that language, which means using the target language frequently is a crucial part of learning another language. In addition, it is possible for second language learners to take it for granted that the ideal teacher of the target language is a native speaker. Taking English language teaching as the example, as some assumptions mentioned by Cummins[2], people might think the more English is taught, the better the results will be and similarly, the standards of English will decline if other languages are used for any significant amount of instructional time.

\subsection{Disadvantages of Monolingual Education}

However, monolingual education still has great limitations. Firstly, from the perspective of the learning process, using only the target language in class requires students to have a certain foundation of this language. If the students lack basic knowledge of the target language, they may have difficulties understanding the teachers' instruction so the learning efficiency of the class would be reduced. Secondly, from the perspective of the learning outcomes, it is not true that native speakers are the "best teachers" of learning another language. By contrast, those non-native speakers who had the experience of learning the target language are better teachers than those native speakers because they have the same position of learning this language instead of acquiring it.

\section{CONCEPTS AND FEATURES OF BILINGUAL EDUCATION}

\subsection{Motivation of Second Language Learners}

Language learners in certain regions with integrative and intrinsic motivation can have a great influence on language learning, which highlights the importance of bilingual education. According to Kormos[10], learners may learn the second language without any internal factors such as interests, they may have objective attitudes toward the second language. For instance, some foreign language learners may learn their L2 just because it is the national or official language, and they have to learn this language in order to adapt to the society in their home country. For example, some English learners learn English just to cope with university classes and complete tasks and exams in English. No matter what the motivation is, second language learning is an important part of education nowadays. As a result, the feasibility and necessity of bilingual education has been brought out.

\subsection{Advantages of Bilingual Education}

One of the advantages of bilingual education is that it can improve proficiency in both languages of learners. The research mentioned in Maniruzzaman[15] suggests that it does not have a long-term adverse influence on students' academic performance in their first language because the transfer between languages can be done by improving understanding of concepts, literacy skills and learning strategies of acquiring two languages. According to Maniruzzaman[15], this is a common situation due to several studies that have proved that this is true in languages that are completely different. Also, bilingual education can improve learners' target language understanding through comparing concepts and explanations in their first language. Contextual knowledge is provided to students in order to make the target language easier for students to understand[15]. As this passage states, if the language learners are already familiar with certain concepts in their first language, the shift to another language of the same concepts can be done in a more effective way. As a result, the efficiency of learning another language can be improved because it needs less time to explain in the target language and students have already gained knowledge in their mother tongue. In conclusion, bilingual education is beneficial for students, and students' cognitive skills gains significance through it. Students can make progress in both of their languages by improving their understanding of bilingual instructions, which can make the teaching and learning process more effective. Therefore, bilingual education programs should be delivered in schools.

\section{TRANSLANGUAGING}

\subsection{Future Changes in Education}

Due to Covid-19, more online courses have been provided and students from different regions can have classes together. More universities are training their staff to have online teaching skills because there will be more online learning in the future, which makes it easier to deliver online courses to people around the world and expand the market customers of universities. There are more online programs, and they will start delivering online courses to people around the world. For the university, this is good because potentially they will expand their market customers. For many students, it 
might have more advantages because the fees might be cheaper. If students can study online, they do not need to live on campus or use the facilities in universities, so the cost will be less. In addition, they will give other people in countries that have weaker education systems more opportunities of accessing more resources and knowledge.

\subsection{The Importance of Trans-languaging}

As is mentioned by Lin[14], trans-languaging has gained great influence in the fields of bilingual and multilingual education, and it has become a popular topic in applied linguistics and TESOL (Teaching English to Speakers of Other Languages). However, there is still some concern about whether this is just another trend in the field of language education, and how translation studies differ from traditional studies under the condition of code-switching, code-mixing, or code-alternation[13][14]. There are controversies and challenges in trans-languaging research, policy and practice. Some researchers doubt the need for such a concept when the familiar concepts of trans-coding and code-mixing already provide a framework for understanding the use of multiple languages[1].

Actually, the term "translation" does give researchers and educators a more changeable and dynamic view of language though it seems to look like code-mixing/code-switching[14]. As Conteh [3] states, the recent discussion of trans-language is closely related to the existing reappraisal of "mother tongue use"[9] in the language classroom in English teaching.

It is often assumed that foreign language pedagogy and first language pedagogy are two independent systems. However, there is a growing awareness that second or foreign language teaching should not be easily distinguished with the assistance of the first language of the learners, which highlights the importance of trans-languaging in language learning classes. This means using the first language as a teaching tool can help the learners gain higher proficiency in L2 learning. According to Lin [14], trans-languaging has certain pedagogical functions. Firstly, a more comprehensive understanding of the subject matter can be developed through trans-languaging, for the educators can explain certain concepts in learners' first language so they can have a better understanding of these concepts. As Cummins [2] states, although certain obvious aspects such as pronunciation or fluency of different languages differ from each other, these languages still have cognitive and academic proficiency which is common though it is less intuitionistic. Secondly, using more than one language in classes can help students develop their weaker language for they can understand some of the grammar rules by comparing the target language with their native language. Additionally, trans-languaging can promote a deeper and fuller understanding of the content and helps learners to connect the weaker language with the dominant one at the same time [8]. Thirdly, trans-languaging can help the integration of fluent speakers with early learners due to they can communicate through both native language and target language.

From the educators' perspective, there is still a misunderstanding of the role of the mother tongue. While negative perceptions of the use of the mother tongue stem from multilingual classrooms, especially in English-speaking environments with a mix of linguistic backgrounds and cultures, some language teachers still tend to mistakenly try to apply beliefs and practices anchored in quite different contexts unrealistically to English contexts, without considering the conditional differences that exist between contexts [1]. It is important to recognize and acknowledge that methods developed in an ESL or multilingual EFL environment do not instinctively apply to a monolingual EFL classroom. Most of these courses are usually taught by teachers who are not native English speakers, and in most cases, learners come from the same language background and culture that teachers also share [16]. Therefore, the role of learners' first language should be considered as a crucial part of the language learning process, due to its significance in helping the learners better understand the context in the foreign language.

\section{CONCLUSION}

This essay has discussed different means of teaching in education and makes comparison between these different types of teaching methods. After evaluating and comparing different approaches that are used in foreign language education, it is clear that trans-languaging plays a significant role in education because of the need of using more languages in a cross-culture environment. This essay just evaluates monolingual education and bilingual education in the field of second language learning, and it needs more research in other field of education.

\section{ACKNOWLEDGMENTS}

First of all, I would like to express my gratitude to all those who helped me during the writing of this essay. I gratefully acknowledge the help of my thesis advisor, Ms Huang, who has offered me valuable suggestions in the academic studies. In the preparation of this essay, she has spent much time reading through each draft and provided me with inspiring advice. Without her patient instruction insightful criticism and expert guidance, the completion of this thesis would not have been possible.

Second, I also owe a special debt of gratitude to Professor Gearon, from whose devoted teaching and enlightening lectures! I have gained much knowledge in 
the field of education and benefited a lot and academically prepared for the thesis.

Last, I should finally like to express my gratitude to my beloved family for their loving considerations and great confidence in me all through these years and have always been helping me out of difficulties and supporting without a word of complaint. I also owe my sincere gratitude to my friends and my fellow classmates who gave me their help and time in listening to me and helping me work out my problems during the difficult course of the thesis.

\section{REFERENCES}

[1] Celik, S. (2008). Opening the door: An examination of mother tongue use in foreign language classrooms. Hacettepe Üniversitesi Eğitim Fakültesi Dergisi, 34(34), 75-85.

[2] Cummins, J. (2005, September). Teaching for cross-language transfer in dual language education: Possibilities and pitfalls. In TESOL Symposium on dual language education: Teaching and learning two languages in the EFL setting (pp. 1-18). Estambul: Universidad BogaziciTurquía.

[3] Conteh, J. (2018). Translanguaging. ELT Journal, 72(4), 445-447.

[4] Degollado, E. D. (2018). Translanguaging with multilingual students: Learning from classroom moments, Edited by O. García \& T. Kleyn, New York, NY: Routledge, 2016, 236 Pages, 49.95(paperback), 160.00 (hardcover). ISBN-13: 978-1138906983.

[5] Edwards, J. (1994). Multilingualism. London: Routledge.

[6] Ellis, E. (2006). Monolingualism: The unmarked case. Estudios de Sociolingüística, 7(2), 173-196.

[7] Fasold, R. W., \& Connor-Linton, J. (Eds.). (2014). An introduction to language and linguistics. Cambridge university press.

[8] García, O., \& Wei, L. (2014). Translanguaging and education. In Translanguaging: Language, bilingualism and education (pp. 63-77). Palgrave Pivot, London.

[9] Hall, G. and G. Cook. 2012. 'Own-language use in language teaching and learning'. Language Teaching 45/3: 271-308.

[10] Kormos, J. (2012). The role of individual differences in L2 writing. Journal of second language writing, 21(4), 390-403.

[11] Lewis, G., Jones, B., \& Baker, C. (2012a). Translanguaging: Developing its conceptualisation and contextualisation. Educational Research and Evaluation, 18(7), 655-670.

[12] Lin, A. M. Y. (2013a). Classroom code-switching: Three decades of research. Applied Linguistics Review, 4(1), 195-218

[13] Lin, A. M. Y. (2013b). Towards paradigmatic change in TESOL methodologies: Building plurilingual pedagogies from the ground up. TESOL Quarterly, 47(3), 521-545.

[14] Lin, A. M. (2020). Introduction: Translanguaging and translanguaging pedagogies. In Translanguaging in Multilingual English Classrooms (pp. 1-9). Springer, Singapore.

[15] Maniruzzaman, M. (2003). The use of the mother tongue in the EFL classroom: Learners' reaction. Harvest: Jahangirnagar Studies in Literature, 18, 43-58.

[16] Murakami, I. (2001). The 'bridging strategy': Active use of learners' first language in second language teaching. Humanising Language Teaching, 3(6). Retrieved July 15, 2007, from http://www.hltmag.co.uk/nov01/mart3.htm 